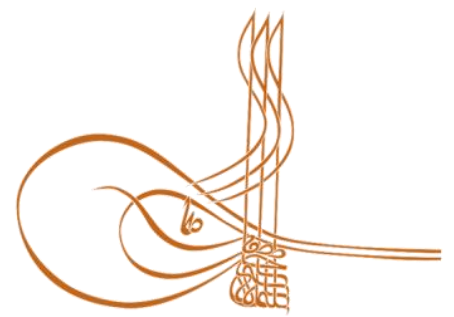

www.turkishstudies.net/economy
Turkish Studies - Economics, Finance, Politics

eISSN: $2667-5625$

Research Article / Araştırma Makalesi

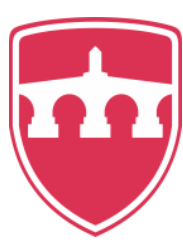

INTERNATIONAL BALKAN

UNIVERSITY

Sponsored by IBU

\title{
İmalat Sektöründeki İşletmelerin Finansal Performanslarının Ölçülmesi: Bir Veri Zarflama Analizi (VZA) Uygulamasi*
}

\author{
The Measurement of the Financial Performances of the Companies in Manufacturing Industry: \\ Application of a Data Envelopment Analysis (DEA)
}

\author{
Bülent Y1ldız $^{* *}$ - Ceyda Yerdelen Kaygın ${ }^{* * *}$ - Tuncer Yılmaz ${ }^{* * *}$
}

\begin{abstract}
The objective of the study is to measure comparatively the financial performances of the enterprises operating in the manufacturing sector. For this purpose, different financial ratios have been calculated by using some figures from the financial statements of 155 of the manufacturing industry enterprises listed in BIST. Six of these financial ratios (current ratio, debt-equity ratio, debt asset ratio, inventory turnover rate, credit turnover rate and the ratio of cost of sales to net sales) are determined as input variables, while the other six (fixed asset turnover, equity profitability, profitability of assets, main operating profit margin and market value-book value ratio) are determined as output variables. Companies that do not have continuity of data are excluded from the study. Nevertheless, they were not included in the scope of the studies in which the financial ratios had negative values. The resulting financial ratios are defined as inputoutput variables to be used as the basis for Data Envelopment Analysis (DEA), which allows the use of multiple variables together for the performance measurements of the decision-making units (DMUs) studied. The determined input-output variables (financial ratios) were transferred to the Frontier Analyst program in order to calculate the efficiency values of the enterprises. For the analysis, CCR model with CRS (Constant Return Scale) approach and BCC models with variable return (VRS) approach were used. In both models, output-oriented results were obtained in addition to input-oriented results of enterprises. According to the
\end{abstract}

\footnotetext{
* Bu makale, 3-5 Mayıs 2018 tarihlerinde Bayburt’ta gerçekleştirilen Uluslar arası Uygulamalı İşletme, Yönetim ve Ekonomi Araştırmaları Sempozyumu'nda sözlü bildiri olarak sunulmuştur.

** Dr. Öğr. Üyesi, Aydın Adnan Menderes Üniversitesi, Nazilli İktisadi ve İdari Bilimler Fakültesi, Uluslararası Ticaret ve Finansman Bölümü

Asst. Prof. Dr. Aydın Adnan Menderes University/Faculty Of Economics And Administrative Sciences

ORCID 0000-0001-6358-8620

bulent.yildiz@adu.edu.tr

**** Dr. Öğr. Üyesi, Kafkas Üniversitesi, İktisadi ve İdari Bilimler Fakültesi, Uluslararas1 Ticaret ve Lojistik Bölümü

Asst. Prof. Dr., Kafkas University, Faculty Of Economics and Administrative Sciences

ORCID 0000-0001-9544-9991

ceydayerdelen@gmail.com

**** Öğr. Gör., Kafkas Üniversitesi, Susuz Meslek Yüksek Okulu, Finans Bankacılık ve Sigortacılık Bölümü

Lecturer, Kafkas Üniversity, Susuz Vocational Collage, Department of Finance, Banking and Insurance

ORCID 0000-0001-8956-5814

y1lmaz-tuncer@hotmail.com

Cite as/ Atıf: Yıldız, B., Yerdelen Kaygın, C., Yılmaz, T. (2020). İmalat sektöründeki işletmelerin finansal performanslarının ölçülmesi: bir veri zarflama analizi (VZA) uygulaması, Turkish Studies - Economy, 15(1), 613628. https://dx.doi.org/10.29228/TurkishStudies.39429

Received/Geliş: 22 October/Ekim 2019

Accepted/Kabul: 25 March/Mart 2020

Checked by plagiarism software

Copyright $(C$ INTAC LTD, Turkey

Published/Yayın: 30 March/Mart 2020

CC BY-NC 4.0
} 
results of the analysis, 30 (29\%) of the 104 enterprises included in the study were found to be effective according to CCR model activity scores in both input and output oriented approaches. According to BCC model analysis results, 49 (47\%) of the enterprises have both input and output efficiency scores.

Structured Abstract: In today's world it will not be wrong to say that businesses are in a tough competition both locally and globally. Businesses are trying to control their costs while increasing their sales and increasing their profitability. While enterprises are looking for cheap financing sources, they make an important effort to increase the market value of the enterprise and aim to minimize their inputs and maximize their output in order to increase their performance. In this study, it is aimed to measure the financial performances of 155 manufacturing industry enterprises whose shares are traded on BIST for 2012-2017 period with Data Envelopment Analysis (DEA). The five-year averages of the 12 financial ratios calculated to be used in DEA were applied. Businesses whose data are not continuous and have negative average value are excluded from the data set. Thus, 104 companies and 1248 observations of calculated financial ratios were included in the analysis. Among the financial ratios used for analysis, the current ratio, financing ratio, financial leverage ratio, inventory turnover rate, receivables turnover rate and the ratio of cost of sales to net sales are input (as variables), net profit margin, return on equity, asset profitability, main operating profit margin, market value-book value ratio and fixed asset turnover ratio are determined as output variables.

It is determined that there is a positive and meaningful relationship between some of the input and output variables selected for Data Envelopment Analysis and a negative and significant relationship between some of them. There was no statistically significant relationship between some variables. Among the variables, there was a negative and significant relationship between current ratio and debt-equity, debt-asset and receivables turnover rate. It was found that there is a positive and significant relationship between the current ratio and net profit margin and return on assets. While there is a negative and significant relationship between debt-equity ratio and current ratio, net profit margin, return on assets and main operating profit margin, there is a positive and significant relationship between debt-asset ratio. While there is a positive and statistically significant relationship between the debt-asset ratio and the ratio of cost of sales to net sales, there is a contradictory and significant relationship between the debt-asset ratio and the net profit margin, the profitability of the assets and the main operating profit margin. While there was a positive and significant relationship between inventory turnover and fixed asset turnover and net profit margin, it was found that there was a positive and significant relationship between the turnover rate of receivables and the ratio of cost of sales to net sales. It is found that there is a negative and significant relationship between the ratio of cost of sales to net sales and net profit margin, return on equity, return on assets and main operating profit margin.

The mean value of the CCR model efficiency score, which is a constant return to scale (CRS) model, from the input-oriented analysis results of DEA, was calculated as $70.72 \%$. The lowest input-oriented CCR score was found at Kristal Kola with $29.82 \%$. According to the BCC approach, which has a variable return model (VRS) according to the scale and expresses technical efficiency, the average efficiency value for 104 enterprises was $93.38 \%$. According to BCC, the lowest technical efficiency score was observed in Klimasan Klima with a value of $72.81 \%$. Scale activity is calculated by dividing the total activity by scale activity. According to the results of input-oriented scale effectiveness, the average score was $74.87 \%$ and the lowest score was $33.45 \%$ for Berkosan Insulation. The CCR model, which is a constant return to scale (CRS) model derived from DEA's output-oriented analysis results, calculated the average value of the efficiency scores as $70.72 \%$. The lowest CCR score was found to be $29.82 \%$ for Crystal Cola. According to the BCC approach, which has a variable return model (VRS) according to the scale and expresses technical efficiency, the average efficiency value was calculated as $80.21 \%$ for 104 enterprises and the lowest technical efficiency score was observed in Crystal Cola enterprise with $32.27 \%$. According to the results oriented scale efficiency results, the average score was $88.83 \%$ and the lowest score was $36.32 \%$ for Çimentaş. It was found that 30 (29\%) of the enterprises included in the study were effective according to both input and output oriented CCR model, while the remaining $74(71 \%)$ were found to have activity scores below 100 and moved away from the activity boundary at different levels. In the BCC model, it was found that $49(47 \%)$ of the 104 enterprises included in the study were effective in both input and output orientations, whereas 55 (53\%) enterprises were not effective. However, although the effective rate of operations obtained by the BCC model is equal in input and output orientation, the efficiency values of enterprises vary. In the BCC model, in the input-oriented analysis of enterprises, the average activity score of 104 enterprises was 93.37, whereas in the output-oriented model, this value decreased to 80.21 . The effectiveness value of the effective enterprises is 
calculated as 100. In the CCR / BCC model, 30 enterprises (29\%) were effective in terms of input and output and 74 enterprises $(71 \%)$ were ineffective. According to the results obtained from the DEA method, CRS and output oriented total efficiency (CCR) model, the efficiency values of the effective and ineffective enterprises are given together. According to the obtained activity scores, enterprises with 100 activity scores are considered effective and enterprises with a score below 100 are considered as ineffective enterprises. According to the data in the table, enterprises that have a value of 100 are considered effective and enterprises with a value below 100 are considered as ineffective enterprises. According to the scores obtained from 104 enterprises within the scope of the study, it was observed that 30 enterprises had 100 scores expressing effectiveness, 29 enterprises were in the range of 50 to 97, and 25 enterprises had a score below 50. The results of DEA are obtained from the variable-return (VRS) and output-oriented technical efficacy (BCC) model. According to the data in the table, it was found that 49 out of 104 enterprises had 100 activity scores, 39 enterprises were in the range of 50 to 97, and 16 enterprises had a value below 50. According to the output-oriented CCR model among the 104 manufacturing enterprises included in the study, it shows the group average of the potential improvement percentages that input and output variables should perform in order to be effective (74 enterprises). According to the research results, firstly ineffective enterprises should increase their net profit margin by $43.96 \%$. In addition, it was determined that ineffective enterprises should increase their return on assets by $17.93 \%$, return on equity by $15.55 \%$, main operating profit margin by $7.23 \%$, market value book value by $5.96 \%$ and fixed asset turnover by $5.22 \%$. However, it was determined that ineffective enterprises should decrease their, current ratio - $0,15 \%$, debt equity ratio - $0,32 \%$, debt asset ratio $-0,67 \%$, inventory turnover rate $-0,20 \%$, receivables turnover rate $-1,53 \%$ and ratio of cost of sales to net sales $-1,29 \%$.

Keywords: BIST, Financial Ratios, Data Envelopment Analysis, Efficiency

JEL Codes: C14, G10, L25, M1

Öz: Çalışmanın amacı imalat sektöründe faaliyet gösteren işletmelerin finansal performanslarının karşılaştırmalı olarak ölçülmesidir. Bu amaçla BIST'te işlem gören imalat sanayi işletmelerinin 155 tanesinin finansal tablolarına ait bazı rakamlar kullanılarak farklı finansal oranlar hesaplanmıştır. Elde edilen bu finansal oranlardan altı tanesi (cari oran, borç-özkaynak oranı, borç aktif oranı, stok devir hızı oranı, alacak devir hızı oranı ve satışların maliyetinin net satışlara oranı) girdi değişkenleri olarak belirlenirken diğer altı tanesi (duran varlık devir hızı, özkaynak karlılığı, aktiflerin karlılığg, esas faaliyet kar marjı ve piyasa değeridefter değeri oranı) ise çıktı değişkenleri olarak belirlenmiştir. Verileri süreklilik arz etmeyen işletmeler çalışma kapsamından çıkartılmıştır. Bununla birlikte finansal oranları itibariyle negatif değere sahip olan işletmelerde çalışma kapsamına alınmamıştır. Elde edilen finansal oranlar, üzerinde çalışılan karar verme birimlerinin (KVB) performans ölçümleri için birden çok değişkenin birlikte kullanımına imkân tanıyan Veri Zarflama Analizi'ne (VZA) esas olacak girdi-çıktı değişkenleri olarak tanımlanmışlardır. Belirlenen girdiçıktı değişkenleri (finansal oranlar) işletmelerin etkinlik değerlerinin hesaplanabilmesi amaciyla Frontier Analyst programına aktarılmıştır. Analiz için VZA'nın ölçeğe göre sabit getiri (CRS-Constant Return Scale) yaklaşımına sahip CCR modeli ile ölçeğe göre değişken getiri (VRS-Variable Return Scale) yaklaşımına sahip BCC modelleri kullanılmıştır. Her iki model içinde işletmelerin girdi yönelimli sonuçlarının yanında çıktı yönelimli sonuçları da elde edilmiştir. Analiz sonuçlarına göre çalışmaya alınan 104 işletmeden 30'unun (\%29) girdi ve çıktı yönlü her iki yaklaşım içinde CCR modeli etkinlik skorlarına göre etkin oldukları tespit edilmiştir. BCC modeli analiz sonuçlarına göre ise işletmelerin 49'unun (\%47) yine hem girdi yönlü hem de çıktı yönlü etkinlik skoruna sahip oldukları tespit edilmiştir.

Anahtar Kelimeler: BİST, Finansal Oranlar, Veri Zarflama Analizi, Etkinlik

Jel Kodları: C14, G10, L25, M1

\section{Giriş}

Günümüz dünyasında işletmelerin hem yerel hem de küresel anlamda zorlu bir rekabet içerisinde olduğunu söylemek yanlış olmayacaktır. Bu rekabetin temelinde son iki yüzyıldır yaşanan gelişmeler yatmaktadır. Özellikle buharlı makinelerin keşfi ile başlayan birinci sanayi devrimini, elektriğin icadını takip eden kitle üretim yöntemleri ve üretimde makineleşme ikinci 
sanayi devrimi olarak karşımıza çıkmaktadır. 1950'li yıllardan sonra gelişen teknolojiler ile birlikte üretim süreçlerine katılan makine ve cihazların daha nitelikli oluşu, yarı iletkenlerin teknolojik cihazların içerisinde akıllı entegre sistemler olarak yer alması, otomasyon sistemleri, nano teknolojiler, yazılımlar, bilgisayarlar ve internetin kullanımının yaygınlaşması üçüncü sanayi devrimi olarak karşımıza çıkmakta ve şimdilerde dünya dördüncü sanayi devrimine geçişin provalarını yapmaktadır. Bu güne kadar yaşanan bu baş döndürücü gelişmeler hem iş yaşamını, hem de işletmelerin işleyişi ve yapısını büyük ölçüde değiştirmiş ve dönüştürmüştür.

Artık başarılı işletmeler sadece ürün üretimi veya satışı ile ilgilenmek yerine ham maddenin girişinden, ürün olarak müşterinin eline ulaştığ dönem boyunca yürütülen bütün iş ve işlemleri müşteriye karşı bir sorumluluk olarak görmektedirler. İşletmeleri buna iten en önemli unsur hiç şüphesiz ki "bilgi ekonomisi" olarak tarif edilen son dönemin ekonomik modeli ile birlikte gelen hem yerel piyasalarda hem de küresel piyasalarda yaşanan rekabettir. Pazar payı edinebilmek veya var olan pazar payını koruyabilmek için işletmelerin kendi adlarına rekabet şartlarını iyileştirmeleri ve ellerini güçlendirmeleri gerekmektedir. Bu amaçla işletmeler bir yandan maliyetlerini kontrol altına almaya çalışırken bir yandan da satışlarını artırma ve bu satışlardan elde ettiği kârlılığı yükseltme çabası içindedirler. İşletmeler bir yandan ucuz finansman kaynakları ararken bir yandan da işletmenin piyasa değerini yükseltmek için önemli bir çaba içine girmektedirler. İşletmeler girdilerini minimize etmeye çalışırken bir yandan da çıktılarını maksimize etmeyi hedeflemektedirler. Bu bağlamda işletmelerin yürüttükleri bütün faaliyetlerin neticesinde ortaya çıkan performans ve bu performansın rakip işletmelerle olan ilişkisi hem şirketi yönetenler hem de yatırımcılar açısından çok önemlidir.

Firma yöneticileri firmalarının plan ve hedeflerinden sapmaları ortaya koymak ve rekabet ettikleri diğer işletmelere göre durumlarını görmek maksadıyla dönemsel olarak çeşitli ölçüm ve değerlemelere ihtiyaç duymaktadırlar (Sayım ve Yalama, 2008; 89). Rekabetin hem yerelde hem de küresel anlamda çok zorlu geçtiği ve yaşandığ bu dönemde işletmeler faaliyetlerini daha planlı ve kontrollü olarak yürütmelidirler. Bu nedenle günümüzde yaşanan bu rekabet, işletmeleri sahip oldukları kaynakları en optimal bir şekilde kullanmaya zorlamaktadır. Söz konusu kaynakların optimal bir şekilde kullanımını sağlamak için ise işletmelerin faaliyet gösterip rekabet ettikleri sektör içerisinde kendi performanslarını göreli olarak değerlendirmeleri gerekmektedir. Bununla birlikte işletmelerin sektör içerisinde etkinlik sınırında yer almaları için hangi işletmeleri referans almaları gerektiğini de tespit etmeleri gerekmektedir (Atan ve Kıllı, 2005; 1).

İşletmelerin gerek kendi içinde gerekse bulundukları sektör içerisindeki performansını ortaya koymak için kullanılabilecek birçok yöntem ve uygulama mevcuttur. İşletmelerin yürüttükleri faaliyetler neticesinde elde ettikleri finansal raporlar bu performans1 ortaya koyabilecek önemli göstergelerdir. Bu çalışma kapsamında BIST'te faaliyet gösteren imalat işletmelerinin performanslarını ölçmek için finansal oranlar kullanılmıştır. Söz konusu finansal oranlar çoklu girdi-çıktı değişkenin bir arada kullanılmasına imkân tanıyan ve non-parametrik bir yöntem olan Veri Zarflama Analizi (VZA) uygulaması ile yapılmıştır. Analiz için 12 adet finansal oranın 6 tanesi girdi, 6 tanesi ise çıktı değişkenler olarak belirlenmiştir. Çalışma kapsamında etkin olan ve etkin olmayan işletmeler ve etkinlik skorları tespit edilmiştir. Etkinsizlik yüzdeleri bulunarak ne oranda iyileştirmeler yapılması gerektiği tespit edilmiştir.

\section{Literatür}

Labrecque (1996), Amerika Birleşik Devleti'ndeki bazı şehirlerde faaliyet gösteren orta büyüklükte olan ulaşım firmalarının etkinliklerini tespit etmek amacıyla dördü girdi, ikisi ise çıktı değişkeni olmak üzere toplam 6 farklı değişken kullanarak VZA yöntemi ile söz konusu firmaların teknik etkinliklerini ölçmüştür.

Chen (1999), yaptığı çalışmada Çin'de faaliyet gösteren 35 tane büyük çelik üreticisinin çeşitli verilerini kullanarak VZA yöntemi uygulamış, çalışma neticesinde işletmelerin 
etkinliklerinin yükseltilebilmesi için önemli maliyet unsuru olan işçi sayısı ile birlikte diğer maliyet unsuru olan girdilerin azaltılması, çıktıların ise artırılması gerektiği tespit edilmiştir.

Chen, Skully ve Brown (2005), çalışmalarında Çin bankalarının 1993 ile 2000 yılları arasındaki etkinlikleri VZA yöntemi ile analiz edilmiştir. Çalışmaya dâhil edilen 43 banka içerisinden büyük ölçekli kamuya ait bankalar ile ve küçük ölçekli bankaların orta ölçekteki bankalara nazaran daha iyi etkinlik skorlarına sahip oldukları tespit edilmiştir.

Benli Keskin (2006), payları İMKB'de işlem gören imalat sanayi işletmeleri ve sektörel bazda bu işletmelerin performanslarının ölçülmesi üzerinde çalıșmıștır. Araștırma için 2000-2004 y1llarına ait veriler kullanılarak VZA ve Malmquist toplam faktör verimliliği endeks yöntemi ile yapılan analizler sonucunda çalışmaya dahil edilen hiçbir sektörde ortalama değer olarak etkinliğin tam etkinlik düzeyine ulaşamadığ 1 tespit edilmiştir. Çalışmada teknik etkinlik skorlarına göre gıda, tütün ve içki sektörünün nispi olarak en etkin sektör olduğu görülmüştür.

Aras (2006), Türkiye'deki tekstil sektörünün 1992 ile 2003 arasındaki yıllarını kapsayan risk ve etkinlik arasındaki ilişkiyi araştırdığı çalışmasında firmaların etkinlikleri için VZA yöntemini kullanmıştır. Araştırmacı çalışmasında, VZA ile elde edilen etkinlik sonuçları ile risk alma ölçütleri arasında çeşitli devrelerde zıt yönlü bir ilişki olduğunu tespit etmiştir.

Ertuğrul ve Tuş Işı1k (2008) çalışmalarında İMKB 100 (BIST 100) endeksinde yer alan ve metal ana sanayin de faaliyet gösteren 13 işletmenin 2003-2007 yıllarına ait mali tablolarını kullanarak veri zarflama analizi (VZA) uygulaması yapmışlardır. Analizlerini VZA'nın çıktı yönelimli CCR modeline göre yapan araştırmacılar çalışmalarının neticesinde yıllara göre etkin olan ve olmayan işletmeleri tespit etmişlerdir.

Yalama ve Sayım (2008) VZA yöntemini kullandıkları çalışmalarında, 2005 yılı aralık dönemi itibariyle İMKB'de işlem gören imalat işletmelerinin performanslarını ölçmek için sekiz girdi, iki çıktı değişken kullanmışlardır. Girdi ve çıktı değişkenleri olarak işletmelere ait finansal rasyoların kullanıldığı çalışmaya göre imalat işletmeleri için ortalama etkinlik değeri yaklaşık \%84 olarak tespit edilmiştir.

Kaya ve Gülhan (2010) payları İMKB'de işlem gören 25 işletmenin performanslarını VZA ve TOPSIS (Technique for Order Preference by Similarity to Ideal Solution) yöntemlerini kullanarak ölçtükleri çalışmalarında analiz için işletmelerin finansal rasyolarını kullanmışlardır. Metal ve makine sektöründe faaliyet yürüten işletmelerin 2008 finansal krizi öncesi ve sonras1 etkinlik düzeylerinin tespiti amacıyla analiz edildiği çalışmanın VZA sonuçlarına göre, kriz öncesi dönemde işletmelerin yaklaşı \% \% ayında etkin işletme sayısı 14, ikinci üç ayında ise bu sayının 19 (\%75) olduğu tespit edilmiştir. Çalışmaya göre kriz öncesi iki dönem ve kriz döneminin ilk iki üçer aylık diliminde en iyi performansa sahip 6 işletmenin değişmediği görülmüştür.

Kamaruddin ve Abokeresh (2012) VZA yöntemi ile yaptıkları çalışmada, Libya'daki üretim işletmelerinin 2000-2008 dönemine ait etkinlikleri tespit edilmeye çalışılmıştır. Çalışmada özelleştirme öncesi ve özelleştirme sonrası olarak ölçülmeye çalışılan etkinlik sonuçlarına göre işletmelerin özelleştirme sonrası etkinlik skorlarının özelleştirme öncesine göre daha yüksek olduğu tespit edilmiştir.

Contuk vd. (2013) çalışmalarında, İMKB'ye kote olan ve imalat sektörünün farklı alt dallarında faaliyet gösteren 160 işletmenin 2009-2010 yıllarına ait verilerini kullanmak suretiyle bu işletmelerin etkinliklerini VZA yöntemiyle tespit etmişlerdir. Her iki yıl içinde alt sektörler için yapılan etkinlik ölçümleri neticesinde etkin işletme yüzdelerinin yıllara göre ve alt sektörlere göre farklılık gösterdiği tespit edilmiştir. 
Yayar ve Karaca (2014), Türkiye'deki kamu ve özel sektör bankalarından oluşan 37 bankanın etkinliklerini VZA yöntemi kullanarak ölçtükleri çalışmalarında kamu bankalarının özel ve yabancı sermayeli bankalara göre daha etkin olduklarını tespit etmişlerdir.

Erdoğan ve Yıldız (2015) ise çalışmalarında kamu ve özel sektör hastanelerinden oluşan 99 hastanenin etkinliklerini VZA yöntemi ile analiz etmişlerdir. Analiz için belirlenen girdi ve çıktı değişkenlerin hastanelerin finansal tablolarından elde edilen rasyoların kullanıldı ̆̆ çalışmada VZA'nın girdi yönelimli CCR ve BCC modelleri kullanılmıştır. Analiz sonuçlarına göre çalışmaya dâhil edilen özel hastanelerin yarısının, kamu hastanelerinin ise yaklaşık üçte birinin etkin değerlere sahip olduğu görülmüştür.

Benli Keskin ve Karaca (2017), İSO 500'de yer alan 15 işletmenin 2008 küresel finans krizi öncesindeki ve sonrasındaki performanslarını ölçtükleri çalışmalarında analiz yöntemi olarak VZA'yı kullanmışlardır. İşletmelere ait finansal oranların VZA için girdi ve çıktı değişken olarak belirlendiği çalışmanın sonuçlarına göre çalışmaya dâhil edilen işletmelerden sadece birisinin kriz öncesi dönemde etkin olduğu, kriz sonrası dönemde ise iki işletmenin etkin olarak tespit edildiği belirtilmiştir.

\section{Yöntem}

\subsection{Veri Zarflama Analizi}

Firma yöneticileri firmalarının plan ve hedeflerinden sapmaları ortaya koymak ve rekabet ettikleri diğer işletmelere göre durumlarını görmek için dönemsel olarak çeşitli ölçüm ve değerlemelere ihtiyaç duymaktadırlar (Sayım ve Yalama, 2008; 89). Hem yerel ve hem de küresel düzeyde rekabetin çok zorlu geçtiği ve yaşandığı bu dönemde işletmelerin faaliyetlerini daha planlı ve kontrollü yürütmeleri gerektiğini ortaya koymaktadır. Bu nedenle günümüzde yaşanan bu rekabet, işletmeleri sahip oldukları kaynakları en optimal bir şekilde kullanmaya zorlamaktadır. Söz konusu kaynakların optimal bir şekilde kullanımını sağlamak için ise işletmelerin faaliyet gösterip rekabet ettikleri sektör içerisinde kendi performanslarını göreli olarak değerlendirmeleri gerekmektedir. Bununla birlikte işletmelerin sektör içerisinde etkinlik sınırında yer almaları için hangi işletmeleri referans almaları gerektiğini de tespit etmeleri gerekebilmektedir (Atan ve Kıllı, $2005 ; 1)$.

Bugün işletmelerin performans ve etkinliklerinin tespit edilmesinde tek bir model ve yöntemden bahsetmek mümkün değildir. Bu amaçla farklı uygulama ve çalışmalarda performansın farklı yönlerini ön plana çıkartan birçok hesaplama şekli geliştirilmiştir. Bu yöntemler arasında çoklu girdi ve çoklu çıktıların kullanıldığ olmayan yöntemler oldukça yaygın bir kullanım alanına sahiptir (Yolalan, 1993; 5). Söz konusu parametrik olmayan yöntemlerden en yaygın olarak kullanılanı ise Charnes, Cooper ve Rhodes tarafından 1978 yılında geliştirilen Veri Zarflama Analizi yöntemidir. Charnes, Cooper ve Rhodes'in geliştirdikleri ilk model "Ölçekten Sabit Getiri" varsayımı (CRS- Constant to Return Scale) kapsamında olan CCR (Charnes, Cooper, Rhodes) modelidir. Daha sonra ise 1984 y1lında Banker, Charnes ve Cooper tarafindan VRS (Variable Return to Scale) modeli olarak bilinen ve "Ölçekten Değişken Getiri” formunu ifade eden yeni bir model oluşturulmuştur (Demir, vd, 2012:170).

Veri Zarflama Analizi için literatürde birçok tanımlama yapılmıştır. Bunlardan birisi: VZA son yıllarda işletmelerin etkinliklerinin ölçülmesinde sıkça kullanılan ve non parametrik (parametrik olmayan) özelliğe sahip bir analiz yöntemi olarak bilinmektedir. Her bir karar verme biriminin (KVB), referans kümelerdeki etkin işletmeleri dikkate alarak, işletmenin etkin olabilmesi ne oranda optimize edilmesi gerektiğini öne çıkarmaktadır ( Ertuğrul ve Karakaşoğlu, 2005: 61). Bir diğeri: Veri Zarflama Analizi, karar verme birimleri (Decision Making Unit- DMU) olarak isimlendirilen, mal ve hizmet üretimi açısından benzer birimlerin göreli etkinliklerinin ölçülmesi amacıyla geliştirilmiş olan ve parametrik olmayan bir analiz yöntemidir (Kecek, 2010: 64). Başka 
bir tanımda ise VZA, çoklu girdi ve çıktı değişkenleri ile birlikte bu değişkenlerin ortak bir ölçü birimine sahip olmadığı durumlarda işletmelerin veya karar verme birimlerinin göreli etkinliklerinin ölçülmesini amaçlayan matematiksel programlama tabanlı bir analiz yöntemi (Tarım, 2001: 152) olarak ifade edilmiştir.

Veri Zarflama Analizi karar verme birimlerinin göreli etkinliklerinin ölçümünü iki aşamada gerçekleștirir. Birinci aşamada, analize dâhil edilen gözlem kümelerinden en az düzeyde girdi değişkenlerini kullanarak, en fazla çıktı bileşimlerinin elde edilmesini sağlayan en etkin gözlemleri tespit eder. İkinci aşama ise, etkinlik sınırında yer alan karar verme birimlerinin referans olarak alınıp, etkinlik skorları 1'den düşük olan (etkin olmayan) karar verme birimlerinin etkinlik sınırına olan uzaklıklarını ölçer (Yolalan, 1993: 6-7). VZA'nın ana varsayımları, tüm karar verme birimlerinin birbirlerine yakın hedeflerinin olması ve kullanılan girdi ve çıtı değişkenlerinin her bir KVB için aynı anlamı ifade etmesi gerekir. Yani her bir KVB aynı türden girdiler kullanıp, aynı türden çıktılar elde edebilen benzer birimler olmalıdır (Bakırcı, 2014: 12).

VZA'nın parametrik yöntemlere göre sağladığı en önemli avantaj, çoklu girdi ve çıktı değişkenlerinin kullanıldığı çalışmalarda parametrik yöntemlerdeki gibi önceden belirlenen bir analitik üretim fonksiyonunun varlığının öngörülmesi gereksinimi olmadan etkinlik ölçümü yapabilmesidir. Bununla birlikte girdi ve çıktı değişkenleri de birimlerden bağımsızdırlar. Bu ise işletmelerin veya karar verme birimlerinin farklı boyutlarının aynı anda test edilebilmesi imkânını sağlamaktadır (Karsak ve İşcan, 2000: 2). VZA yönteminin sağladığı önemli avantajlardan biride çok kriterli karar verme sürecinin işletilmesi gerektiği durumlarda analiz öncesi belirlenmesi gereken bir analitik üretim fonksiyonunun varlığına ihtiyaç duyulmamasıdır. Bununla birlikte girdi ve çıktı değişkenler ile ölçüm birimleri birbirlerinden bağımsızdırlar. Bu özelliği ile VZA işletmelerin farklı boyutlarının aynı süreç içerisinde ölçülebilmesi imkânını sağlamaktadır (Karsak ve İşcan, 2000: 2).

\subsection{Veri Seti}

Çalışma kapsamında yer alan 155 adet işletmenin 2012-2017 yıllarına ait dönem sonu finansal tablolarını kullanarak her yıl için 12 ayrı finansal oran hesaplanmış ve toplamda 11.160 gözlem elde edilmiştir. Daha sonra altı yıllık bu finansal oranların ortalamaları alınarak VZA için 1.860 adet gözlem elde edilmiştir. Elde edilen bu oranların içerisinde verileri süreklilik arz etmeyen ve negatif ortalama değere sahip işletmeler çıkarılmıştır. Böylece analiz kapsamında yer alan işletme sayısı 104, hesaplanan finansal oranlara ait gözlem sayısı ise 1.248 adet olarak belirlenmiştir.

Çalışmada BİST'de faaliyet gösteren imalat işletmelerinin performanslarını ölçmek için finansal oranlar kullanılmıştır. Söz konusu finansal oranlar çoklu girdi-çıktı değişkenin bir arada kullanılmasına imkân tanıyan ve non-parametrik bir yöntem olan Veri Zarflama Analizi (VZA) uygulaması ile yapılmıştır. Analiz için 12 adet finansal oranın 6 tanesi girdi, 6 tanesi ise çıktı değişkenler olarak belirlenmiştir. Uygulamada VZA'nın hem girdi yönelimli hem de çıktı yönelimli CCR ve BCC yöntemlerinin ikisi de kullanılmıştır.

Analiz için kullanılan finansal oranlardan cari oran, finansman oranı, finansal kaldıraç oranı, stok devir hızı, alacak devir hızı ve satışların maliyetinin net satışlara oranı girdi (değişkenler olarak), net kâr marjı, özkaynak kârlılığı, aktif kârlılık, esas faaliyet kâr marjı, piyasa değeri-defter değeri oranı ve duran varlık devir hızı oranı ise çıktı değişkenler olarak belirlenmiştir. 
Tablo 1: VZA İçin Kullanılan Girdi ve Çıktı Değişkenleri

\begin{tabular}{|c|c|c|c|}
\hline & Finansal Değişkenler & Gösterimi & Açıklama \\
\hline \multirow{6}{*}{$\frac{\overrightarrow{0}}{\vec{z}}$} & Cari Oran & $\mathrm{CO}$ & Dönen varlıkların kısa vadeli kaynaklara oranı \\
\hline & Borç-Özkaynak Oranı & BÖZKO & Toplam borcun özkaynaklara oranı \\
\hline & Borç-Aktif Oranı & BAKTO & Toplam borcun aktiflere oranı \\
\hline & Stok Devir Hızı & SDHZ & Satışların maliyetinin ortalama stoklara oranı \\
\hline & Alacak Devir Hızı & ADHZ & Net satışların ortalama ticari alacaklara oranı \\
\hline & Satışların Maliyeti-Net Satışlar Oranı & SMNSO & Satışların maliyetinin net satışlara oranı \\
\hline \multirow{6}{*}{ 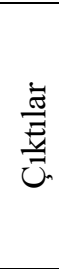 } & Duran Varlık Devir Hızı & DVDHZ & Net satışların duran varlıklara oranı \\
\hline & Net Kâr Marj1 & NKMRJ & Net kârın net satışlara oranı \\
\hline & Özkaynak Kârlılık Oranı & ÖZKO & Net kârın özkaynaklara oranı \\
\hline & Aktif Kârlılık Oranı & AKTKO & Net kârın toplam aktiflere oranı \\
\hline & Esas Faaliyet Kâr Marji & EFKMO & Esas faaliyet kârının net satışlara oranı \\
\hline & Piyasa Değeri-Defter Değeri Oran1 & PDDDO & Piyasa değerinin defter değerine oranı \\
\hline
\end{tabular}

VZA için çalıșmaya dâhil edilen imalat işletmelerinin finansal tablolarından elde edilen girdi ve çıktı değişkenleri ve hesaplanma biçimi Tablo 1'de gösterilmiştir. Girdi ve çıktı değişkenleri belirlenirken literatürde yapılan çalışmalarda kullanılan finansal oranlar dikkate alınarak seçilmiştir.

\section{Bulgular}

Analiz için VZA'nın hem girdi hem de çıktı yönelimli CCR ve BCC modelleri kullanılarak hem girdilerin hem de çıktıların optimizasyonu amaçlanmıştır. İnceleme kapsamında yer alan imalat işletmelerinin 2012-2017 dönemine ait 6 yıllık dönem sonu bilanço ve gelir tablolarından elde edilen finansal oranlara ait tanımlayıcı istatistikler Tablo 2'de verilmiştir.

Tablo 2: Tanımlayıcı İstatistikler

\begin{tabular}{|c|c|c|c|c|c|c|}
\hline & Finansal Değişkenler & $\mathrm{N}$ & Minimum & Maksimum & Ortalama & $\begin{array}{c}\text { Standart } \\
\text { Sapma }\end{array}$ \\
\hline \multirow{6}{*}{$\begin{array}{c}\text { Girdi } \\
\text { Değişkenleri }\end{array}$} & Cari Oran & 104 & 0,61 & 17,70 & 2,37 & 2,02 \\
\hline & Borç-Özkaynak Oranı & 104 & 0,06 & 5,66 & 1,22 & 1,10 \\
\hline & Borç-Aktif Oranı & 104 & 0,05 & 0,85 & 0,44 & 0,19 \\
\hline & Stok Devir Hızı & 104 & 0,91 & 116,98 & 6,79 & 11,65 \\
\hline & Alacak Devir Hızı & 104 & 0,65 & 23,30 & 5,08 & 3,41 \\
\hline & Satışların Maliyeti-Net Satış & 104 & 0,45 & 0,96 & 0,78 & 0,09 \\
\hline \multirow{6}{*}{$\begin{array}{c}\text { Çıktı } \\
\text { Değişkenleri }\end{array}$} & Duran Varlık Devir Hızı & 104 & 0,31 & 31,03 & 4,64 & 5,06 \\
\hline & Net Kâr Marj1 & 104 & 0,00 & 0,30 & 0,09 & 0,08 \\
\hline & Özkaynak Kârlılığı Oranı & 104 & 0,00 & 0,47 & 0,14 & 0,10 \\
\hline & Aktif Kârlılık Oranı & 104 & 0,00 & 0,32 & 0,08 & 0,06 \\
\hline & Esas Faaliyet Kâr Marji & 104 & 0,01 & 0,26 & 0,10 & 0,06 \\
\hline & Piyasa Değeri-Defter Değeri & 104 & 0,36 & 9,89 & 2,13 & 1,77 \\
\hline
\end{tabular}

Şirketlerin finansal oranlarına ait ortalama değerler incelendiğinde, cari oran ortalamaları 2,37 ile ideal değere yakın olduğu, borç özkaynak oranının 1,22 katı olduğu ve işletmelerin ortalama aktiflerinin \%44'ünün borçla finanse edildiği tespit edilmiştir. Sektör, stoklarını yaklaşık olarak yılda 7 (53 günde bir) kez devrettiği, alacaklarını ise yaklaşık 72 günde bir tahsil edebildiği görülmektedir. İşletmeler satışlarının tamamına yakınının kredili olarak gerçekleştirildiği varsayıldığında stok devir hızı (sdhz) ile alacak devir hızı (adhz) arasındaki uyumsuzluk 
(sdhz>adhz) bu haliyle işletmelerin aleyhine işleyecektir. Satışların maliyetinin toplam satışlar içindeki payı ise \%78 olduğu görülmektedir.

Net satışların duran varlıklara oranını gösteren duran varlık devir hızı 4,64 olarak gerçekleşmiştir. Bu oranın yüksek olması istenir. İmalat işletmelerinin 6 yıllık verilerine göre net kâr marj1 \%9, özkaynak kârlılığı \%14, aktif kârlılık \%8, esas faaliyet kâr marjı ise \%10 olduğu görülmektedir. İșletmelerin piyasa değeri-defter değeri oran ortalaması 2,13 olduğu tespit edilmiştir. Bu oran bize, çalışmaya dâhil edilen imalat işletmelerinin piyasa değerinin ortalaması özkaynak ortalamasının iki katından daha fazla olduğunu göstermektedir.

Tablo 3: Değişkenler Arasındaki Pearson Korelasyon Katsayıları

\begin{tabular}{|c|c|c|c|c|c|c|}
\hline & $\begin{array}{l}\text { Cari } \\
\text { Oran }\end{array}$ & $\begin{array}{c}\text { Borç- } \\
\text { Özkaynak } \\
\text { Oranı } \\
\end{array}$ & $\begin{array}{l}\text { Borç- } \\
\text { Aktif } \\
\text { Oran } 1 \\
\end{array}$ & $\begin{array}{c}\text { Stok } \\
\text { Devir Hızı }\end{array}$ & $\begin{array}{c}\text { Alacak } \\
\text { Devir Hızı }\end{array}$ & $\begin{array}{c}\text { Satışların } \\
\text { Maliyeti-Net } \\
\text { Satışlar Oranı }\end{array}$ \\
\hline Cari Oran & 1 & & & & & \\
\hline Borç-Özkaynak Oranı &,$- 404^{* *}$ & 1 & & & & \\
\hline Borç-Aktif Oranı &,$- 606^{* *}$ &, $892^{* *}$ & 1 & & & \\
\hline Stok Devir Hızı &, 129 &,- 088 &,- 159 & 1 & & \\
\hline Alacak Devir Hızı &,$- 200^{*}$ & ,003 & ,123 & ,106 & 1 & \\
\hline Satışların Maliyeti-Net Satışlar &,- 076 &, 142 & $233^{*}$ &,- 057 & $326^{* *}$ & 1 \\
\hline Duran Varlık Devir Hızı & 082 & 152 & ,070 &, $555^{* *}$ &,- 091 & ,114 \\
\hline Net Kâar Marji &, $353^{* *}$ &,$- 509^{* *}$ &,$- 639^{* *}$ & $195^{*}$ &,- 138 &,$- 469^{* *}$ \\
\hline Özkaynak Kârlılık Oranı &, 038 &,- 038 &,- 054 &, 090 &, 102 &,$- 215^{*}$ \\
\hline Aktif Kârlılık Oranı & $267^{* *}$ &,$- 425^{* *}$ &,$- 486^{* *}$ &, 145 &, 022 &,$- 339^{* *}$ \\
\hline Esas Faaliyet Kâar Marj1 & 164 &,$- 288^{* *}$ &,$- 370^{* *}$ &,- 068 &,- 141 &,$- 599^{* *}$ \\
\hline Piyasa Değeri-Defter Değeri Oran1 & ,012 & ,099 &, 043 &,- 004 & ,002 &,- 165 \\
\hline
\end{tabular}

Veri Zarflama Analizi için seçilen girdi ve çıktı değişkenleri arasındaki pearson korelasyon katsayılarını gösteren Tablo 3'deki verilerine göre bazı değişkenler arasında pozitif ve anlamlı, bazı değişkenler arasında negatif ve anlamlı ilişki bulunurken, bazı değişkenler arasında ise istatistiksel olarak anlamlı bir ilişki bulunamamıştır. Değiş̧kenler arasından cari oran ile borç-özkaynak, borçaktif ve alacak devir hızı arasında negatif ve anlamlı bir ilişki bulunmuştur.

Cari oran ile net kâr marjı ve aktiflerin kârlılığı oranları arasında pozitif yönlü ve anlamlı bir ilişkinin var olduğu tespit edilmiştir. borç-özkaynak oranı ile cari oran, net kâr marjı, aktif kârlılık ve esas faaliyet kâr marjı arasında negatif ve anlamlı bir ilişki bulunurken, borç-aktif oranı arasında ise pozitif ve anlamlı bir ilişkinin var olduğu gözlemlenmiştir. Borç-aktif oranı ile satışların maliyetinin net satışlara oranı arasında pozitif yönlü ve istatistiksel olarak anlamlı bir ilişki bulunurken, yine borç-aktif oranı ile net kâr marjı, aktiflerin kârlılığı ve esas faaliyet kâr marjı arasında zıt yönlü ve anlamlı bir ilişkinin varlığı tespit edilmiştir.

Stok devir hızı ile duran varlık devir hızı ve net kâr marjı arasında pozitif yönlü ve anlamlı bir ilişki bulunurken, alacak devir hızı ile sadece satışların maliyetinin net satışlara oranı arasında pozitif yönlü ve anlamlı bir ilişki olduğu ortaya çıkmıştır. Satışların maliyetinin net satışlara oranı ile net kâr marjı, özkaynak kârlılığı, aktif kârlılık ve esas faaliyet kâr marjı arasında negatif yönlü ve anlamlı bir ilişkinin var olduğu tespit edilmiştir. 
Tablo 4: İşletmelerin Etkinlik Sonuçlarına İlişkin Tanımlayıcı İstatistikler

\begin{tabular}{|l|c|c|c|c|c|}
\hline \multicolumn{7}{|c|}{ Model } & N & Minimum & Maksimum & Ortalama & $\begin{array}{c}\text { Standart } \\
\text { Sapma }\end{array}$ \\
\hline \multicolumn{7}{|c|}{ Girdi Yönelimli Sonuçlar } \\
\hline Toplam Etkinlik (CCR) & 104 & 29,82 & 100 & 70,72 & 23,34 \\
\hline Teknik Etkinlik (BCC) & 104 & 72,81 & 100 & 93,38 & 8,10 \\
\hline Ölçek Etkinlik (CCR/BCC) & 104 & 33,45 & 100 & 74,87 & 21,03 \\
\hline \multicolumn{7}{|c|}{ Çıtı Yönelimli Sonuçlar } \\
\hline Toplam Etkinlik (CCR) & 104 & 29,82 & 100 & 70,73 & 23,34 \\
\hline Teknik Etkinlik (BCC) & 104 & 32,27 & 100 & 80,21 & 22,34 \\
\hline Ölçek Etkinlik (CCR/BCC) & 104 & 36,32 & 100 & 88,83 & 15,53 \\
\hline
\end{tabular}

Tablo 4'de görüldüğü üzere VZA'nın girdi yönelimli analiz sonuçlarından elde edilen ve ölçeğe göre sabit getiri (CRS) modeli olan CCR modeli etkinlik skorunun ortalama değeri \%70,72 olarak hesaplanmıştır. Girdi yönelimli en düşük CCR skoruna sahip işletme ise \%29,82 ile Kristal Kola şirketinde olduğu tespit edilmiştir. Ölçeğe göre değişken getiri modeli (VRS) olan ve teknik etkinliği ifade eden BCC yaklaşımına göre ise 104 işletme için ortalama etkinlik değeri \%93,38 çıkmıştır. BCC'ye göre en düşük teknik etkinlik skoru ise \%72,81 değeri ile Klimasan Klima işletmesinde gerçekleştiği gözlemlenmiştir. Ölçek etkinliği ise toplam etkinliğin ölçek etkinliğine bölünmesi ile hesaplanmaktadır. Girdi yönelimli ölçek etkinliği sonuçlarına göre ise ortalama skor \%74,87, en düşük skora sahip işletme ise \% 33,45 ile Berkosan Yalıtım şirketine ait olduğu tespit edilmiştir. Şirketlerin CCR ve BBC modellerine ait girdi yönelimli etkinlik skor tablosu yerine sadece çıktı yönelimli skor tablolarına (Tablo 6 ve Tablo 7) yer verilmiştir.

Tablo 4'de VZA'nın çıktı yönelimli analiz sonuçlarından elde edilen ve ölçeğe göre sabit getiri (CRS) modeli olan CCR modeli etkinlik skorlarının ortalama değeri \%70,72 olarak hesaplandığ1, en düşük CCR skorunun ise \% 29,82 olarak Kristal Kola (Tablo 6) işletmesi için gerçekleştiği görülmektedir. Ölçeğe göre değişken getiri modeli (VRS) olan ve teknik etkinliği ifade eden BCC yaklaşımına göre ise 104 işletme için ortama etkinlik değeri \%80,21 olduğu, en düşük teknik etkinlik skoru ise \%32,27 ile yine Kristal Kola (Tablo 7) işletmesinde gerçekleştiği görülmüştür. Çıktı yönelimli ölçek etkinliği sonuçlarına göre ise ortalama skor $\% 88,83$, en düşük skor ise \% 36,32 ile Çimentaş işletmesine ait olduğu tespit edilmiştir.

Tablo 5: Etkin Olan ve Etkin Olmayan İşletme Sayıları ve Oranları

\begin{tabular}{|c|c|c|c|c|c|c|}
\hline \multirow[t]{2}{*}{ Finansal Etkinlik Sonuçları } & \multicolumn{3}{|c|}{$\begin{array}{l}\text { Girdi Yönelimli Etkinlik } \\
\text { Sonuçları }\end{array}$} & \multicolumn{3}{|c|}{$\begin{array}{c}\text { Çıktı Yönelimli Etkinlik } \\
\text { Sonuçları }\end{array}$} \\
\hline & CCR & $\mathrm{BCC}$ & $\mathrm{CCR} / \mathrm{BCC}$ & $\mathrm{CCR}$ & $\mathrm{BCC}$ & $\mathrm{CCR} / \mathrm{BCC}$ \\
\hline Çalışmaya Dâhil Edilen İşletme & 104 & 104 & 104 & 104 & 104 & 104 \\
\hline Etkin İşletme Sayısı & 30 & 49 & 30 & 30 & 49 & 30 \\
\hline Etkin İşletme Oranı & $29 \%$ & $47 \%$ & $29 \%$ & $29 \%$ & $47 \%$ & $29 \%$ \\
\hline Etkin Olmayan İşletme Sayısı & 74 & 55 & 74 & 74 & 55 & 74 \\
\hline Etkin Olmayan İşletme Oranı & $71 \%$ & $53 \%$ & $71 \%$ & $71 \%$ & $53 \%$ & $71 \%$ \\
\hline
\end{tabular}

Tablo 5'de görüldüğü gibi çalışmaya dâhil edilen işletmelerden 30'unun (\%29) hem girdi hem de çıktı yönelimli CCR modeline göre etkin olduğu, kalan 74 işletmenin (\%71) ise etkinlik skorlarının 100'ün altında değer alarak etkinlik sınırından farklı düzeylerde uzaklaştıkları tespit edilmiştir. BCC modelinde ise çalışmaya dâhil edilen 104 işletmeden 49 tanesinin (\%47) hem girdi hem de çıktı yönelimli olarak etkin olduğu, 55 işletmenin ise (\%53) etkin olmadığı ortaya çıkmıştır. 
Fakat BCC modeli ile elde edilen etkin işletme oranı girdi ve çıktı yönelimde eşit olmasına rağmen işletmelerin etkinlik değerleri farklılık göstermektedir. BCC modelinde işletmelerin girdi yönelimli analizinde 104 işletmenin etkinlik skorlarının ortalaması 93,37 iken çıktı yönelimli modelde ise bu değer 80,21'e düşmüştür. Etkin olan işletmelerin etkinlik değeri 100 olarak hesaplanmıştır. CCR/BCC modelinde ise 30 işletme (\%29) girdi ve yönelimli olarak etkin olduğu, 74 işletme (\%71) ise etkin olmadığ gözlemlenmiştir.

Araştırma kapsamında yer alan işletmelerin çıktı yönelimli CCR modeline göre elde edilen etkinlik skorları Tablo 6'da, BCC modeline göre etkinlik skorları Tablo 7'de sunulmuştur.

Tablo 6: İşletmelerin Çıktı Yönelimli CCR Modeline Göre Etkinlik Skorları

\begin{tabular}{|c|c|c|c|c|c|}
\hline İşletme Ad 1 & $\begin{array}{c}\text { Etkinlik } \\
\text { Değeri }\end{array}$ & İşletme Ad 1 & $\begin{array}{c}\text { Etkinlik } \\
\text { Değeri }\end{array}$ & İşletme $A_{d}$ & $\begin{array}{l}\text { Etkinlik } \\
\text { Değeri }\end{array}$ \\
\hline F-M İzmit Piston & 100 & Ușak Seramik & 83,08 & Pınar Süt & 56,89 \\
\hline Ege Gübre & 100 & Alarko Carrier & 79,82 & Göltas Cimento & 56,01 \\
\hline Ege Endüstri & 100 & Jantsa Jant Sanayi & 79 & Klimasan Klima & 54,91 \\
\hline Adana Cimento (C) & 100 & Gübre Fabrik. & 77,49 & Silverline Endüstri & 54,81 \\
\hline Adel Kalemcilik & 100 & İzocam & 76,95 & Ülker Bisküvi & 52,7 \\
\hline Türk Traktör & 100 & Kardemir (B) & 76,23 & Celik Halat & 51,77 \\
\hline Aslan Cimento & 100 & $\operatorname{Kardemir}(\mathrm{A})$ & 76,23 & Bilici Yatırım & 50,93 \\
\hline İhlas Ev Aletleri & 100 & Kardemir (D) & 76,23 & Saray Matbaacilık & 50,86 \\
\hline Tüpras & 100 & Prizma Press & 75,29 & Bagfas & 50,84 \\
\hline Akçansa & 100 & Nuh Cimento & 75,15 & Petkim & 48,41 \\
\hline Derimod & 100 & Vestel Beyaz Eşya & 73,34 & Parsan & 47,89 \\
\hline Ünye Cimento & 100 & Brisa & 73,09 & Batı Cimento & 47,59 \\
\hline Temapol Polimer Plas. & 100 & Dyo Boya & 72,48 & Bursa Çimento & 46,4 \\
\hline Cimsa & 100 & Ereğli Demir Celik & 72,13 & Coca Cola İcecek & 45,69 \\
\hline Arsan Tekstil & 100 & Ege Seramik & 70,93 & Cemtas & 45,57 \\
\hline Türk Prysmian Kablo & 100 & Anadolu Isuzu & 69,92 & Afyon Cimento & 44,99 \\
\hline Adana Cimento (B) & 100 & Acıpayam Selüloz & 69,83 & Kordsa Global & 44,36 \\
\hline Katmerciler Ekipman & 100 & Erbosan & 69,62 & Anadolu Efes & 42,29 \\
\hline Ford Otosan & 100 & Soda Sanayii & 68,19 & Anadolu Cam & 42,29 \\
\hline Kent Gida & 100 & Pinar Et Ve Un & 67,45 & Gersan Elektrik & 41,75 \\
\hline Mardin Cimento & 100 & Yatas & 66,97 & Batı Söke Cimento & 41,41 \\
\hline Sarkuysan & 100 & Kartonsan & 66,64 & Alkim Kağıt & 39,96 \\
\hline Adana Cimento (A) & 100 & Aksa & 64,35 & Gentas & 39,92 \\
\hline Aygaz & 100 & Menderes Tekstil & 63,24 & Trakya Cam & 39,65 \\
\hline Sönmez Pamuklu & 100 & Kütahya Porselen & 62,74 & Bak Ambalaj & 39,63 \\
\hline T.Tuborg & 100 & Good-Year & 61,72 & Borusan Mannes. & 39,06 \\
\hline Bolu Çimento & 100 & A.V.O.D Gida Ve & 61,61 & Mondi Tire & 38,37 \\
\hline Doğan Gazetecilik & 100 & Sasa Polyester & 61,37 & Ditas Doğan & 38,13 \\
\hline Bosch Fren Sistemleri & 100 & Tümosan Motor ve & 60,42 & Dagi Giyim & 37,03 \\
\hline Otokar & 100 & Arçelik & 59,85 & Çimentaș & 36,32 \\
\hline Hektas & 96,47 & Tat Gida & 59,31 & Bossa & 35,08 \\
\hline Konfrut Gida & 95,83 & Ege Profil & 58,78 & Berkosan Yalıtım & 31,5 \\
\hline Tofas Oto. Fab. & 90,86 & Alkim Kimya & 58,11 & Olmuksan-IP & 31,48 \\
\hline Konya Cimento & 89,6 & Yünsa & 57,73 & Kristal Kola & 29,82 \\
\hline Deva Holding & 85,61 & Vestel & 57,31 & & \\
\hline
\end{tabular}

Tablo 6'da VZA yönteminin ölçeğe göre sabit getirili (CRS) ve çıktı yönelimli toplam etkinlik (CCR) modelinden elde edilen sonuçlara göre etkin olanlar ve olmayanlar işletmelerin etkinlik değerleri birlikte verilmiştir. Elde edilen etkinlik skorlarına göre, 100 etkinlik skoruna sahip olan işletmeler etkin, 100'ün altında bir skora sahip olan işletmeler ise etkin olmayan işletmeler olarak kabul edilmektedir. Tabloda yer alan verilere göre 100 değerini alan işletmeler etkin, 100'ün altında değere sahip olan işletmeler ise etkin olmayan işletmeler olarak kabul edilmektedir. Çalışma kapsamında yer alan 104 işletmeye ait elde edilen skorlarına göre 30 
işletmenin etkinliği ifade eden 100 skoruna sahip olduğu, 29 işletmenin 50 ile 97 aralığında olduğu, 25 işletmenin ise 50’nin altında bir skora sahip olduğu gözlemlenmiştir.

Tablo 7: İşletmelerin Çıktı Yönelimli BCC Modeline Göre Etkinlik Skorları

\begin{tabular}{|c|c|c|c|c|c|}
\hline İşletme Ad1 & $\begin{array}{c}\text { Etkinlik } \\
\text { Değeri }\end{array}$ & İşletme Adı & $\begin{array}{c}\text { Etkinlik } \\
\text { Değeri }\end{array}$ & İşletme Ad1 & $\begin{array}{c}\text { Etkinlik } \\
\text { Değeri }\end{array}$ \\
\hline Adana Çimento (C) & 100 & Türk Prysmian & 100 & Tümosan Mot. ve & 68,07 \\
\hline Saray Matbaacılık & 100 & Ünye Çimento & 100 & Aksa & 64,38 \\
\hline Mondi Tire Kutsan & 100 & T.Tuborg & 100 & Kordsa Global & 63,79 \\
\hline Çimentaș & 100 & Türk Traktör & 100 & Sasa Polyester & 62,91 \\
\hline Prizma Press & 100 & Adel Kalemcilik & 100 & Silverline Endüstri & 61,87 \\
\hline Dagi Giyim & 100 & Cimsa & 100 & Good-Year & 61,78 \\
\hline Ușak Seramik & 100 & F-M İzmit Piston & 100 & Klimasan Klima & 61,53 \\
\hline Kartonsan & 100 & Aslan Cimento & 100 & Borusan & 61,04 \\
\hline Yünsa & 100 & Doğan & 100 & Arçelik & 60,84 \\
\hline Gübre Fabrik. & 100 & Bolu Çimento & 100 & Bilici Yatırım & 60,69 \\
\hline Vestel & 100 & Bosch Fren & 100 & Ülker Bisküvi & 60,37 \\
\hline Adana Cimento (B) & 100 & Kent Gida & 100 & Alkim Kimya & 59,8 \\
\hline Yataș & 100 & Adana Cimento & 100 & Tat Gida & 59,55 \\
\hline Parsan & 100 & Sönmez Pamuklu & 100 & Afyon Cimento & 56,74 \\
\hline Konya Cimento & 100 & Hektaș & 96,54 & Göltaș Cimento & 56,14 \\
\hline Dyo Boya & 100 & Tofaș Oto. Fab. & 91,36 & Batı Çimento & 53,02 \\
\hline Menderes Tekstil & 100 & Kardemir (B) & 90,34 & Çemtaș & 51,3 \\
\hline Konfrut Gida & 100 & $\operatorname{Kardemir}(\mathrm{A})$ & 89,95 & Bagfaș & 51,06 \\
\hline Mardin Çimento & 100 & Kardemir (D) & 89,95 & Coca Cola İçecek & 48,91 \\
\hline Arsan Tekstil & 100 & A.V.O.D Gida & 86,93 & Petkim & 48,52 \\
\hline Pinar Et Ve Un & 100 & Brisa & 81,82 & Bursa Cimento & 48,15 \\
\hline Aygaz & 100 & Ege Profil & 81,79 & Gentaș & 46,95 \\
\hline İhlas Ev Aletleri & 100 & Kütahya Porselen & 80,62 & Anadolu Cam & 44,96 \\
\hline Akçansa & 100 & Alarko Carrier & 80,17 & Trakya Cam & 44,36 \\
\hline Jantsa Jant Sanayi & 100 & İzocam & 78,75 & Batısöke Cimento & 43,77 \\
\hline Tüpraş & 100 & Çelik Halat & 77,56 & Bak Ambalaj & 42,69 \\
\hline Derimod & 100 & Ege Seramik & 75,49 & Berkosan Yalıtım & 42,5 \\
\hline Ford Otosan & 100 & Nuh Çimento & 75,2 & Anadolu Efes & 42,48 \\
\hline Deva Holding & 100 & Anadolu Isuzu & 74,97 & Gersan Elektrik & 41,79 \\
\hline Ege Endüstri & 100 & Soda Sanayii & 74,88 & Bossa & 40,28 \\
\hline Ege Gübre & 100 & Vestel Beyaz & 73,47 & Alkim Kağıt & 39,97 \\
\hline Temapol Polimer & 100 & Erbosan & 73,07 & Ditaș Doğan & 39,33 \\
\hline Sarkuysan & 100 & Acıpayam & 72,9 & Olmuksan-IP & 32,69 \\
\hline Otokar & 100 & Ereğli Demir & 72,84 & Kristal Kola & 32,27 \\
\hline Katmerciler Ekipman & 100 & Pinar Süt & 69,1 & & \\
\hline
\end{tabular}

Tablo 7'de ise VZA'nın ölçeğe göre değişken getirili (VRS) ve çıktı yönelimli teknik etkinlik (BCC) modelinden elde edilen sonuçlar yer almaktadır. Tablodaki verilere göre 104 işletmeden 49'unun 100 etkinlik skoruna sahip olduğu, 39 işletmenin 50 ile 97 aralığında olduğu, 16 işletmenin ise 50 skorunun altında bir değere sahip olduğu tespit edilmiştir. 
Şekil 1: Çıktı Yönelimli Toplam Etkinlik (CCR) Modeline Göre Potansiyel İyileştirme Oranları

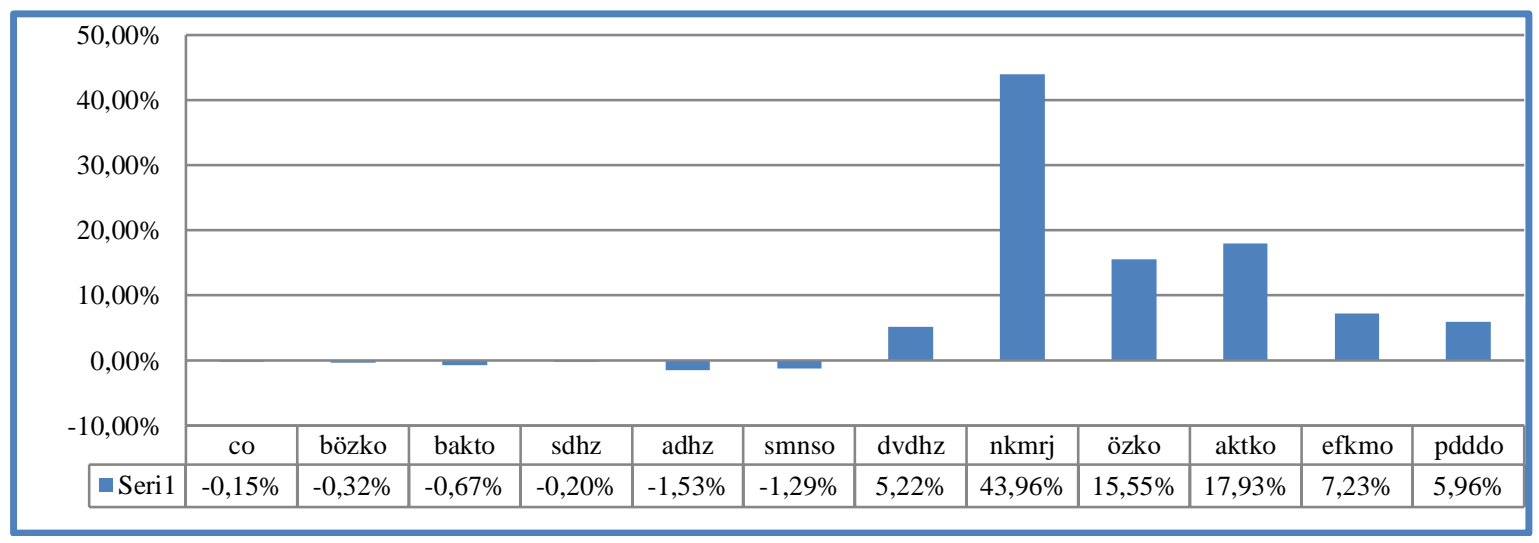

Şekil 1'de gösterilen veriler çalışmaya dâhil edilen 104 imalat işletmesi içerisinden çıktı yönelimli CCR modeline göre etkin olmayan işletmelerin (74 işletme) etkin olabilmeleri için girdi ve çıktı değişkenlerinde yapmaları gereken potansiyel iyileştirme yüzdelerinin grup ortalamasını göstermektedir. Şekil 1'de yer alan sonuçlara göre, etkin olmayan işletmeler başta net kâr marjını \%43,96, aktif kârlılıklarını \%17,93, özkaynak kârlılığın \%15,55, esas faaliyet kâr marjını \%7,23, piyasa değeri defter değeri oranını $\% 5,96$, duran varlık devir hızını ise $\% 5,22$ oranında artırmaları gerektiği tespit edilmiştir. Ayrıca işletmeler cari oranlarını -\%0,15, borç özkaynak oranını -\%0,32, borç aktif oranını $-\% 0,67$, stok devir hızını -\%0,20, alacak devir hızını - \%1,53, satışlarını maliyetinin net satışlara oranını -\%1,29 oranında azaltmaları gerekir.

\section{Sonuç}

İşletmeler her gün artan ve zorlaşan rekabet koşullarında varlıklarını sürdürebilmeleri için sahip oldukları varlık ve kaynakları en optimal düzeyde kullanmaları kaçınılmaz olmuştur. Varlık ve Kaynakların kullanım verimliliği ve ortaya konulan performansın yeterliliği tespit etmek için sürekli olarak ölçüm ve değerleme yapmakla mümkündür. $\mathrm{Bu}$ bağlamda işletmelerin gerek parametrik gerekse non-parametrik yöntemler ile çeşitli performans kriterlerini kullanarak analiz etmeleri geleceğe dönük daha sağlıklı ve gerçekçi kararlar almalarını sağlamaktadır.

Çalışmada, BİST'de pay senetleri işlem gören imalat sanayii işletmelerinin 2012-2017 yıllarına ait finansal raporları kullanılarak elde edilen finansal oranların ortalamaları hesaplanarak Veri Zarflama Analizi uygulamasına tabi tutulmuştur. Yapılan analizler sonucunda işletmelerin hem girdi hem de çıktı yönelimli modeller kullanılarak yorumlanabilir sonuçlar elde edilmiştir.

VZA'nın girdi yönelimli analiz sonuçlarından elde edilen ve ölçeğe göre sabit getiri (CRS) modeli olan CCR modeli etkinlik skorunun ortalama değeri \%70,72 olarak hesaplanmıştır. Girdi yönelimli en düşük CCR skoruna sahip işletme ise \%29,82 ile Kristal Kola şirketinde olduğu tespit edilmiştir. Ölçeğe göre değişken getiri modeli (VRS) olan ve teknik etkinliği ifade eden BCC yaklaşımına göre ise 104 işletme için ortalama etkinlik değeri \%93,38 çıkmıştır. BCC'ye göre en düşük teknik etkinlik skoru ise \%72,81 değeri ile Klimasan Klima işletmesinde gerçekleştiği gözlemlenmiştir. Ölçek etkinliği ise toplam etkinliğin ölçek etkinliğine bölünmesi ile hesaplanmaktadır. Girdi yönelimli ölçek etkinliği sonuçlarına göre ise ortalama skor $\% 74,87$, en düşük skora sahip işletme ise \% 33,45 ile Berkosan Yalıtım şirketine ait olduğu tespit edilmiştir.

VZA'nın çıktı yönelimli analiz sonuçlarından elde edilen ve ölçeğe göre sabit getiri (CRS) modeli olan CCR modeli etkinlik skorlarının ortalama değeri \%70,72 olarak hesaplandığı, en düşük CCR skorunun ise \% 29,82 olarak Kristal Kola işletmesi için gerçekleştiği görülmektedir. Ölçeğe göre değişken getiri modeli (VRS) olan ve teknik etkinliği ifade eden BCC yaklaşımına göre ise 104 işletme için ortama etkinlik değeri \%80,21 olduğu, en düşük teknik etkinlik skoru ise \%32,27 ile yine Kristal Kola işletmesinde gerçekleştiği görülmüştür. Çıktı yönelimli ölçek etkinliği 
sonuçlarına göre ise ortalama skor $\% 88,83$, en düşük skor ise $\% 36,32$ ile Çimentaş işletmesine ait olduğu tespit edilmiştir.

Çalışmaya dâhil edilen işletmelerden 30'unun (\%29) hem girdi hem de çıktı yönelimli CCR modeline göre etkin olduğu, kalan 74 işletmenin (\%71) ise etkinlik skorlarının 100'ün altında değer alarak etkinlik sınırından farklı düzeylerde uzaklaştıkları tespit edilmiştir. BCC modelinde ise çalışmaya dâhil edilen 104 işletmeden 49 tanesinin (\%47) hem girdi hem de çıktı yönelimli olarak etkin olduğu, 55 işletmenin ise (\%53) etkin olmadığı ortaya çıkmıştır. Fakat BCC modeli ile elde edilen etkin işletme oranı girdi ve çıktı yönelimde eşit olmasına rağmen işletmelerin etkinlik değerleri farklılık göstermektedir. BCC modelinde işletmelerin girdi yönelimli analizinde 104 işletmenin etkinlik skorlarının ortalaması 93,37 iken çıktı yönelimli modelde ise bu değer 80,21'e düşmüş̧ür. Etkin olan işletmelerin etkinlik değeri 100 olarak hesaplanmıştır. CCR/BCC modelinde ise 30 işletme (\%29) girdi ve yönelimli olarak etkin olduğu, 74 işletme (\%71) ise etkin olmadığı gözlemlenmiştir.

VZA yönteminin ölçeğe göre sabit getirili (CRS) ve çıktı yönelimli toplam etkinlik (CCR) modelinden elde edilen sonuçlara göre etkin olanlar ve olmayanlar işletmelerin etkinlik değerleri birlikte verilmiştir. Elde edilen etkinlik skorlarına göre, 100 etkinlik skoruna sahip olan işletmeler etkin, 100'ün altında bir skora sahip olan işletmeler ise etkin olmayan işletmeler olarak kabul edilmektedir. Tabloda yer alan verilere göre 100 değerini alan işletmeler etkin, 100'ün altında değere sahip olan işletmeler ise etkin olmayan işletmeler olarak kabul edilmektedir. Çalışma kapsamında yer alan 104 işletmeye ait elde edilen skorlarına göre 30 işletmenin etkinliği ifade eden 100 skoruna sahip olduğu, 29 işletmenin 50 ile 97 aralığında olduğu, 25 işletmenin ise 50'nin altında bir skora sahip olduğu gözlemlenmiştir.

VZA'nın ölçeğe göre değişken getirili (VRS) ve çıktı yönelimli teknik etkinlik (BCC) modelinden elde edilen sonuçlar yer almaktadır. Tablodaki verilere göre 104 işletmeden 49'unun 100 etkinlik skoruna sahip olduğu, 39 işletmenin 50 ile 97 aralığında olduğu, 16 işletmenin ise 50 skorunun altında bir değere sahip olduğu tespit edilmiştir.

Çalışmaya dâhil edilen 104 imalat işletmesi içerisinden çıktı yönelimli CCR modeline göre etkin olmayan işletmelerin (74 işletme) etkin olabilmeleri için girdi ve çıktı değişkenlerinde yapmaları gereken potansiyel iyileştirme yüzdelerinin grup ortalamaları hesaplanmıştır. Bu sonuçlara göre, etkin olmayan işletmeler başta net kâr marjını \%43,96, aktif kârlılıklarını \%17,93, özkaynak kârlılığını \%15,55, esas faaliyet kâr marjını \%7,23, piyasa değeri defter değeri oranını $\% 5,96$, duran varlık devir hızını ise $\% 5,22$ oranında artırmaları gerektiği tespit edilmiştir. Ayrıca işletmelerin cari oranlarını $-\% 0,15$, borç özkaynak oranını $-\% 0,32$, borç aktif oranını $-\% 0,67$, stok devir hızını -\%0,20, alacak devir hızını -\%1,53, satışlarını maliyetinin net satışlara oranını -\% 1,29 oranında azaltmaları gerektiği de tespit edilmiştir.

Çalışmada elde edilen sonuçlara göre işletmelerin çıtı yönelimli CCR modelinde $\% 29$, BCC modelinde ise $\% 47$ oranında bir etkinliğe sahip oldukları ortaya çıkmıştır. Ortaya çıkan bu farkl11ık ise CCR ve BCC modellerinden birisinin "Ölçeğe Göre Sabit Getiri-CCR" modellemesini, diğerinin ise "Ölçeğe Göre Değişken Getiri-BCC" modellemesini esas alarak hesaplama yapmasıdır.

\section{Kaynakça}

Aras, G. (2006). Avrupa Birliği Açısından ve Dünya Pazarlarına Uyum Açısından Türk Tekstil ve Konfeksiyon Sektörünün Rekabet Yeteneği (Finansal Yaklaşım), İstanbul: Mart Matbaası.

Atan, M. ve Kıllı, M. (2005). Etkinlik/Verimlilik Çalışmalarında Kullanılan Veri Zarflama Analizi Üzerine Karşılaştırmalı Yaklaşımlar. 4. İstatistik Kongresi, İstatistik Mezunları Derneği ve Türk İstatistik Derneği, Antalya. 
Bakırcı F., Shiraz, S. E. ve Sattary, A. (2014), Bist'da Demir, Çelik Metal Ana Sanayii Sektöründe Faaliyet Gösteren İşletmelerin Finansal Performans Analizi: VZA Süper Etkinlik ve Topsis Uygulaması, Ege Akademik Baklş, Cilt: 14 Sayı: 1 Ocak 2014 ss. 9-19

Benli Keskin, Y. \& Karaca, S.S. (2017). 2008 Kriz Öncesi Ve Sonrası İso 500 Sanayi İşletmelerinin Etkinliklerinin Ölçümü: Veri Zarflama Analizi Yaklaşımı, Gazi İktisat ve İsletme Dergisi, 3(1), 19-34

Charnes, A., Cooper, W.W, ve Rhodes, E. (1978). "Measuring the efficiency of decisions making units", European Journal of Operation Research, 2: 429-444.

Charnes, A. Cooper, W.W., ve Rhodes, E. (1981). "Evaluating Programme and Managerial effciency: An application of Data Envelopment analaysis to program follow through, Management Science, 27: 668-696.

Chen, X., Skully, M., Brown, K. (2005), "Banking Efficiency in China: An Application of DEA to Pre- and Post Deregulation Era: 1993-2000", China Economic Review, 16, 229-245.

Contuk, Filiz Y., Burucu Hümeyra. ve diğerleri. (2013) Measurement of Financial Performance in Production Sector, Sakarya İktisat Dergisi,2013/4, ss.63-84

Demir, P., Derbentli, Ö., Sakarya, E., (2012) "Kars İlinde Bulunan Mandıraların Etkinliğinin Veri Zarflama Analizi İle Ölçülmesi”, Kafkas Üniversitesi Veteriner Fakültesi Dergisi, 18 (2), 69-176.

Destafanis, S. ve Sena, V. (2007). "Patterns of Corporate Governace and Techinical Efficiency in Italian Manufacturing", Published online in Winley InterScience, 28: 27-40.

Erdoğan, M., \& Yıldız, B. (2015). Sağlık İşletmelerinde Finansal Oranlar Aracılığıyla Performans Ölçümü: Hastanelerde Bir Uygulama. Kafkas Üniversitesi İktisadi ve İdari Bilimler Fakültesi Dergisi, 6 (9), 129-148.

Ertuğrul, İ., Karakasoğlu, N., "Evaluation of service quality in the higher education with data envelopment analysis (DEA) and its application in the departments of the faculty of economics and administrative sciences", International Conference on Business, Management \& Economics in a Changing World, İzmir, 2005.

Kaya, A., \& Gülhan, Ü. (2010). Küresel Finansal Krizin İşletmelerin Etkinlik ve Performans Düzeylerine Etkileri: 2008 Finansal Kriz Örneği. Ístanbul Üniversitesi Iktisat Fakültesi Ekonometri ve İstatistik Dergisi, 11, 61-69.

Kamaruddin, B.H., \& Abokeresh, M.S.M. (2012). The Performance of Privatized Firms: Empirical Analysis for Libya. International Review of Business Research Papers, 8 (6), 134-148.

Karsak, E.E., İşcan, F., (2000), "Çimento Sektöründe Göreli Faaliyet Performanslarının Ağırlıklı Kısıtlamaları ve Çapraz Etkinlik Kullanılarak Veri Zarflama Analizi İle Değerlendirilmesi”, Endüstri Mühendisliği Dergisi, Cilt : 11, Say1 : 3, ss: 2 - 10.

Kecek, G. (2010). Veri Zarflama Analizi, Teori ve Uygulama Örneği, Ankara, Siyasal Kitapevi.

Labrecque, H.J. (1996). Measurement of Efficiency in Urban Mass Transit via A Data Envelopment Analysis, Master of Arts, The University of New Brunswick, in the Department of Economics.

Mahadevan, R. (2002), "A DEA Approach to Understanding the Productivity Growth of Malaysia's Manufacturing Industries", Asia Journal of Management, 19: 587-600. 
Sayım, M. ve Yalama, A. (2008). "Veri Zarflama Analizi İle İmalat Sektörünün Performans Değerlendirmesi": Dokuz Eylül Üniversitesi İktisadi ve İdari Bilimler Fakültesi Dergisi, Cilt 23, Sayı 1: 89-107.

Tarım, A., Veri Zarflama Analizi: Matematiksel Programlama Tabanlı Göreli Etkinlik Ölçüm Yaklaşımı, Sayıștay Yayın İsleri Müdürlüğü, Araștırma / İnceleme / Çeviri Dizisi: 15, Ankara, 2001.

Yolalan, R. (1993). Işsletmelerarası Göreceli Etkinlik Ölçümü, Ankara: Milli Prodüktivite Merkezi Yayınları, No:483. 